Portland State University

PDXScholar

$5-1-1970$

\title{
Validation of the orthogonal dimensions underlying the ICL and the octant constellations assumed to be their measure
}

Donald Edward Lange

Portland State University

Follow this and additional works at: https://pdxscholar.library.pdx.edu/open_access_etds Let us know how access to this document benefits you.

Recommended Citation

Lange, Donald Edward, "Validation of the orthogonal dimensions underlying the ICL and the octant constellations assumed to be their measure" (1970). Dissertations and Theses. Paper 946.

https://doi.org/10.15760/etd.946

This Thesis is brought to you for free and open access. It has been accepted for inclusion in Dissertations and Theses by an authorized administrator of PDXScholar. Please contact us if we can make this document more accessible: pdxscholar@pdx.edu. 
AN ABSTRACT OF THE THESIS OF Donald Edward Lange for the Master of Science in Psychology presented December 17, 1969.

Title: Validation of the Orthogonal Dimensions Underlying the ICL and the Octant Constellations Assumed to be Their Measure

APPROVED BY MEMBERS OF THE THESIS COMMITTEE:

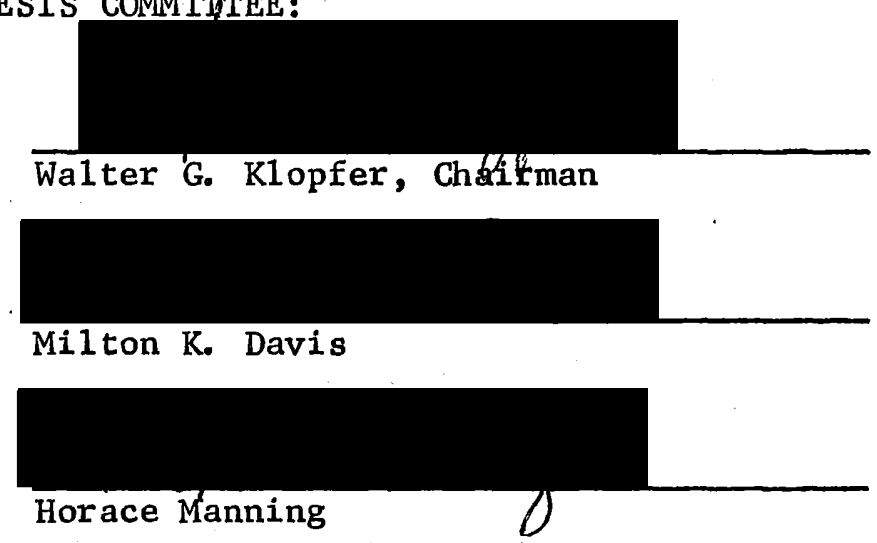

Validity of the orthogonal dimensions underlying the Interpersonal Check List (ICL) and the octant constellations assumed to be their measure was investigated by inferential design. Experimental conditions consisted of 4 role-played videotapes produced so that the interpersonal behavior of the main character would illustrate the 4 poles of the ICL's 2 bipolar dimensions -- Dominance-Submission and Love-Hostility. $\underline{\text { Ss }}$ were 200 students enrolled in 8 beginning-psychology summer classes, Each class viewed, via closed-circuit TV, only 1 of the 4 videotapes; then members were asked to describe the main character viewed, by using an ICL form IV. Protocols were scored by a computer package of the author's writing. Resulting profiles from classes seeing the same tape were pooled to form 4 treatment groups corresponding to the 4 poles of the ICL, then statistically compared by means of a multivariate analogue 
to analysis of variance. Hypotheses concerning octant constellation comparisons were tested by the Tukey (b) procedure. Results support the assumption that 2 bipolar dimensions underly the ICL and that original formulations of LaForge and Suczek concerning the interpersonal variables taken to be their measure are correct. Results can be taken only as an indirect validation of summary scores Dom and Lov. Differences between these findings and previous published findings were noted and discussed. 
VALIDATION OF THE ORTHOGONAL DIMENSIONS UNDERLYING THE ICL AND THE OCTANT CONSTELIATIONS ASSUMED TO BE THEIR MEASURE

by

DONAID EDWARD LANGE

A thesis submitted in partial fulfillment of the requirements for the degree of

MASTER OF SCIENCE

in

PSYCHOLOGY

Portland State University

1970 


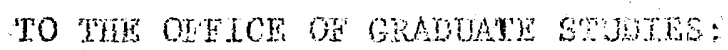

The members of che comotate appove the thesis of Dondd How range presented December 17,1969
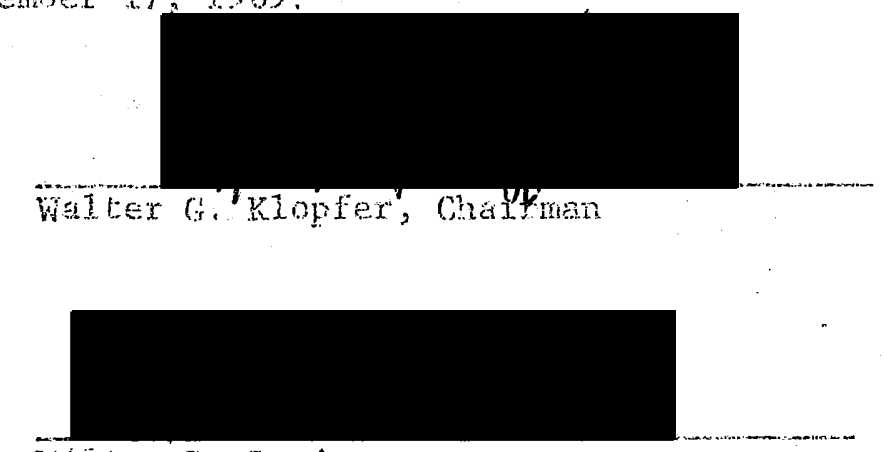

Mijton $\mathrm{K}$. Devis.

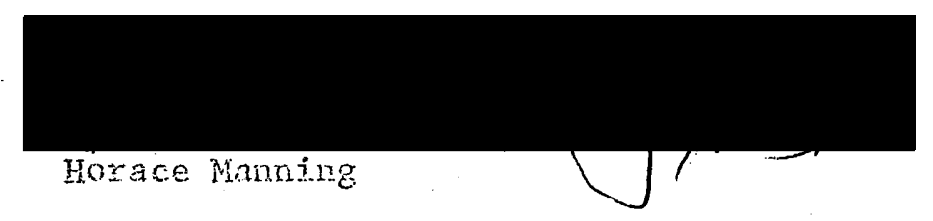

ATPOOVW:

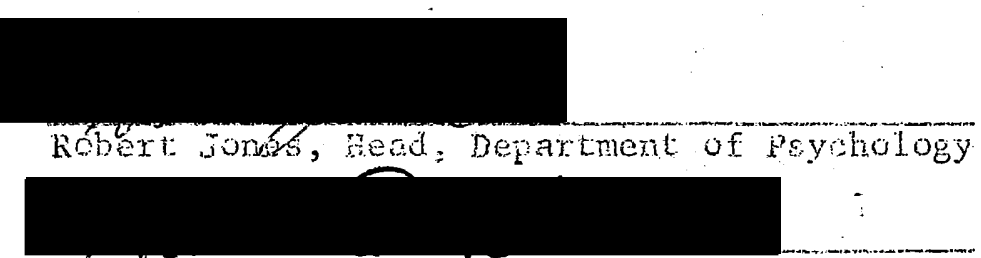

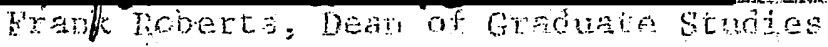

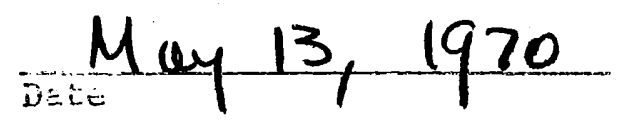




\section{ACKNOWLEDGMENTS}

The following research was supported in part by Portland State University's Department of Psychology; the Computer Center, which handled data processing; and the Center for the Moving Image, which produced the videotapes used in this research.

The author wishes to thank the following people, whose fine acting made the videotapes possible: Pat Bush, Milton Davis, Tom Ear1y, Rod Lee, John Lounsbury, and Mary Rose Wesley.

A specia1 acknowledgment is due the following for their aid, advice, and encouragement: Bob Walker, from the Center for the Moving Image; Pat Bush, John and Karen Lounsbury; Frank and Mary Rose Wesley; my wife, Kay; and the members of my committee, Walter G. Klopfer, Milton K. Davis, and Horace Manning. 
ACKNOWLEDGMENTS . . . • • . . . . . . . • •

LIST OF TABLES . . . . . . . . . . . . . . . . . v v

LIST OF FIGURES . . . . . . . . . . . . . . . . vi v vi vi v

INTRODUCTION ..................... . . . . . 1

METHOD . . . . . . . . . . . . . . 6

Subjects . . . . . . . . . . . . 6

Conditions . . . . . . . . . . . . . 6

Procedure .................. . . . . 7

Analysis of the Data ............. . . . 8

RESULTS . . . . . . . . . . . . . . . . . 10

General Hypotheses . . . . . . . . . 10

Specific Hypotheses . . . . . . . . . . 13

DISCUSSION . . . . . . . . . . . . . 20

REFERENCES . . . . . . . . . . . . . . . . . . 22

APPENDIX .......................

Instructions ... . . . . . . . . . . . 24

Interpersonal Check List . . . . . . . . . 25 


\section{LIST OF TABLES}

TABIE

PAGE

1 Analysis of Variance Testing the General Hypotheses ...

2 Multiple Comparisons between Group Sums on Octant Constellations Expressing ICL Dimensions --DOMINANCE . . . . . . . . . . . . .

3 Multiple Comparisons between Group Sums on Octant Constellations Expressing ICL Dimensions --HOSTILE . . . . . . . . . . . . .

4 Multiple Comparisons between Group Sums on Octant Constellations Expressing ICL Dimensions -.SUBMISSIVE ...................

5 Multiple Comparisons between Group Sums on Octant Constellations Expressing ICL Dimensions -..

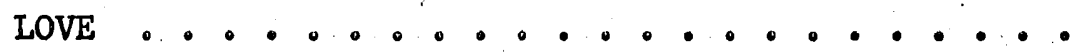




\section{LIST OF FIGURES}

1 Interpersonal Check List illustrating the classification of interpersonal behaviors into 8 and 16 variable categories . . . . . .

2 Group by octant interaction . . . . . . . . . 
The Interpersona1 Check List (ICL), devised by LaForge and Suczek (1955) as a self-administering adjective check 1 ist, was created specifically to measure personality variables consistent with the Interpersonal Personality system emerging from research conducted by Leary and co-workers at the Kaiser Foundation Hospital (Leary, 1957). The ICL, and the system behind it, were rationally devised and assume a circumplex of 16 or 8 interpersonal variables ordered around 2 orthogonal bipolar dimensions, Dominance-Submission and LoveHostility (Figure 1). In order to analyze empirically the substructure of this multidimensional personality instrument, several investigators have undertaken various factor analytic studies (LaForge, 1963; Briar \& Bieri, 1963; Bentler, 1965; Foa, 1961; Owens, 1967; Wiggins, 1961). Typically, when summary scores - Average Intensity (AIN) and Number of Items Checked (NIC) - are included as variables in the analysis, investigators find 2 factors to exhaust the variance: Dominance, lying on the vertical axis, and Love, on the horizontal (LaForge, 1963). However, several studies have shown 3 factors to emerge and the factors to lie differently about the circumplex (Briar \& Bieri, 1963; LaForge, 1963). LaForge (1963) explains that these discrepant findings are due to not including AIN and NIC as variables in the factor analysis. To this point, one should add the possible effects of differential samples and factor rotation.

A study typical of those finding 3 factors when AIN and NIC have not been included, is that of Briar and Bieri (1963). These authors defined 3 factors: Factor I, considered Dominance, and defined by 


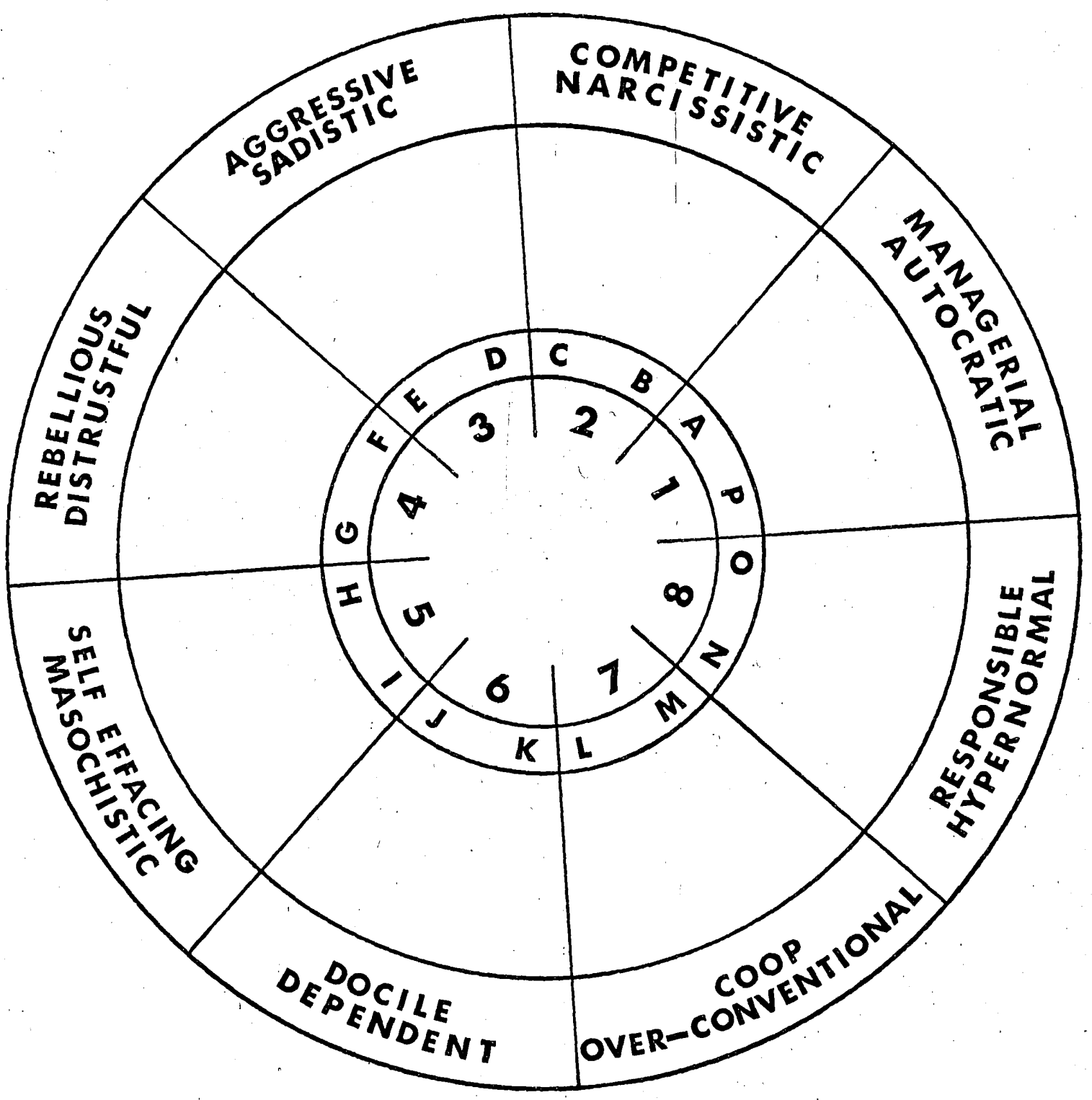

Figure 1. Interpersonal Check List illustrating the classification of interpersonal behaviors into 8 and 16 variable categories. 
octants 2,3, and less so by 1; Factor II, located on the Love dimension, and most clearly defined by octants 7 and 8; finally Factor III, tentatively labeled "inferiority feelings," was more difficult to identify, but was best defined by octant 5 and less clearly by 4 and 6 . Briar and Bieri concluded that their results were generally consistent with Leary and his co-workers' assumption that the ICL measures 2 principle and orthogonal dimensions, Dominance and Love. Yet on the basis of their analysis, a third factor not explicit in Leary's system could be identified. The authors were not certain about the reliable existence of this third factor, however, and suggested that it may be a pseudo-factor.

To this writer, what is more interesting, is beyond the discrepancies between factor analytic findings: specifically, the difference between Briar and Bieri's findings and the formulations of LaForge and Suczek in regards to the way in which the separate octant or 16 th scores should be combined in computing the summary scores Dominance (DOM) and Love (LOV) (Briar \& Bieri, 1963; LaForge \& Suczek, 1955).

Summary scores DOM and LOV, are assumed to adequately summarize an ICL profile in terms of the underlying orthogonal dimensions. Computation of the scores is performed by means of the rationally derived formulae:

when using 16 th scores,

$$
\begin{aligned}
& \mathrm{LOV}=\mathrm{M}-\mathrm{E}+.924(\mathrm{~N}+\mathrm{L}-\mathrm{D}-\mathrm{F})+.707(\mathrm{O}+\mathrm{K}-\mathrm{C}-\mathrm{G})+.383(\mathrm{P}+\mathrm{J}-\mathrm{B}-\mathrm{H})^{1} \\
& \mathrm{DOM}=\mathrm{A}-\mathrm{I}+.924(\mathrm{~B}+\mathrm{P}-\mathrm{H}-\mathrm{J})+.707(\mathrm{C}+\mathrm{O}-\mathrm{G}-\mathrm{K})+.383(\mathrm{D}+\mathrm{N}-\mathrm{F}-\mathrm{L})
\end{aligned}
$$

$1_{\text {The letters used in the formulae designate ICL variables; for }}$ their meaning please see Figure 1. 
or using octant scores,

$\mathrm{LOV}=\mathrm{LM}-\mathrm{DE}+.7(\mathrm{NO}-\mathrm{BC}-\mathrm{FG}+\mathrm{JK})$

$\mathrm{DOM}=\mathrm{AP}-\mathrm{HI}+.7(\mathrm{NO}+\mathrm{BC}-\mathrm{FG}-\mathrm{JK})$.

As seen from the formulae, these involve the addition and subtraction of 16 th or octant scores consistent with the dimensionality they express. Finally, the quantities are weighted by sine-posine values in order to maintain the circumplex system. But on the basis of Briar and Bieri's findings, octant or 16 th scores assumed to be measures of a bipolar dimension are not necessarily suggested by factor analysis. Further, they conclude, that the constants and weights assumed by LaForge and Suczek do not seem essential to the computation of DOM and LOV, and may in fact be inappropriate in view of the factor loadings found.

In an effort to validate their findings, Briar and Bieri employed written statements about an individual, weighted in the direction of the

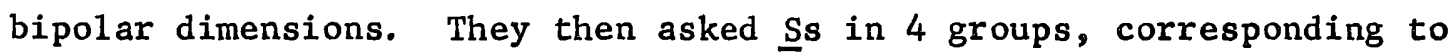
the 4 poles, to describe the individual on the basis of the information provided. However, this author feels that a flaw in their design seriously weakens the suggested validation of their factor analytic findings. Basically the error in their design was the use of a modified ICL adjective 1ist, quite remote from any recognized ICL form, as a validation instrument. By so changing the form they may claim partial validation of their findings as it applies to this modified form, but not to an actua1 ICL.

One need not belabor design errors, however, but rather offer a more acceptable investigation plan. The idea and need for validation of the underlying dimensions is a sound one; factor analytic investigations 
are adequate as a descriptive tool, but an inferential investigation seems always in order when validating rational constructions such as the ICL.

Therefore, the intent of this study was to validate, from "Leve1 I" data. (i.e., Public Communication - an individual as others see him) (Leary, 1957), the bipolar dimensions taken to underly the ICL and the octant constellations assumed to measure them. More specifically, the general hypotheses are that: 1) the profiles arising from ICL protocols

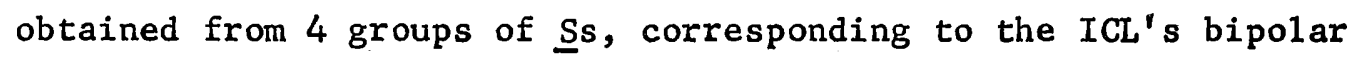
dimensions, Dominance-Submission and Love-Hostility, wil1 be significantly nonparallel; and 2) the profiles of the groups will not be on the same level.

The specific hypotheses are that: 1) groups lying on the same bipolar dimension will differ on octant constellations taken as measures of that dimension; and 2) no consistent differences on octant constellations are predicted between groups 1ying on dimensions which are orthogonal to each other.

These preceding hypotheses will be discussed in more detail later under Analysis of Data. 
METHOD

Subjects

Ss consisted of 218 students enrolled in summer session beginningpsychology classes. These $\underline{\text { Ss }}$ were not randomly selected as individuals but rather taken together as a whole class and administered the materials as a group.

Eight classes were randomly selected from the possible beginningpsychology summer classes and then each was randomly assigned to one of 4 treatment groups, with groups representing the 4 poles of the ICL: Dominance, Submission, Love, and Hostility. Since summer classes were small having about 25 students in each, the 4 groups were composed of 2 classes each.

For statistical purposes it was planned that each treatment group would consist of 50 Ss. However, after administration it was found that Ss totaled 18 more than needed; therefore 18 of the $\underline{S} s^{\text {p }}$ protocals were random1y discarded to obtain an equal number of $\underline{\text { s }}$ in each group. Conditions

Four role-played videotapes, scripted to be illustrative of the 4 poles of the dimensions, Dominance-Submission and Love-Hostility, were produced for later presentation in rooms equipped with closed-circuit TV. ${ }^{2}$ Each of these tapes was composed of the same 5 interpersonal situations and varied only in the dimensionality of interpersonal behavior displayed by the central character. That is, the same actors and interpersonal situations were used throughout the 4 tapes; only the ${ }^{2}$ Copies of these tapes are available from the Center for the Moving Image, Portland State University. 
principle character changed his interpersonal tactics, while the secondary characters remained constant in theirs.

Each tape was approximately 11 minutes in length and presented the interpersonal situations in this order: a) Main Character (MC) and his boss in conference; b) MC in a work scene with secretaries; c) MC and another employee during a coffee break; d) MC and his wife at home; and e) MC and wife in a parent-teacher conference. Procedure

Upon assembling for class, Ss were told that they were going to be participants in psychological research; E was then introduced. If their room was suitably equipped with closed-circuit TV then administration procedures began immediately, if not they were moved to a suitable room.

Materials consisting of a No. 2 pencil, a standard form No. 511 IBM 1230 optica1-scan answer sheet with precoded ID, and a Form IV ICL with attached instructions were passed out to each of the $\underline{S}$.

The $\underline{E}$ told $\underline{S}$ shat he was interested in studying the use of the ICL for describing other people and they would be using it to do so. They were then asked to follow along as E read the instructions (Appendix). After reading the instructions, $\underline{S} s$ were asked if they had any questions about what they were supposed to do or the way in which the ICL was to be used, or how to mark the answer sheet. If there were questions, they were answered, and presentation of the selected videotape began. Each class viewed only one of the 4 video-tapes depicting the ICL's poles: Dominance, Submission, Love, and Hostility. Hence, 
when the classes were pooled, the study was comprised of 4 groups of $\underline{S}$, each corresponding to one of the poles of the 2 bipolar dimensions, Dominance-Submission and Love-Hostility, underlying the ICL. Analysis of the data

Al1 ICL protocols were optically read on an IBM 1230 optical scanner and their answers punched on data cards using an IBM 534 card punch, with the special 1230 code. Data cards were then computerscored by a system package of the author's writing; and resulting 16th scores were summed to octants for use in the statistical techniques.

General hypotheses were tested by means of a multivariate analogue based on the classical two-factor analysis of variance design with repeated measures (Greenhouse \& Geisser, 1959). In this design octant scores are treated as if they are individual test scores forming a single profile. Such a design allows the testing of three hypotheses: a) Do the groups have the same shape, i.e., do the groups arise from populations having parallel group profiles? b) Are the group profiles on the same level, i.e., do the groups arise from populations having the same group means? and c), of lesser importance, Do the octants have the same means?

The multiple comparison procedure used to test differences between groups on selected octant constellations was Tukey (b), a compromise between the Tukey (a) and the Newman-Keuls method (Winer, 1962). The Tukey (b) procedure allows one to test all possible pair-wise comparisons by ordering the means along their range. The Critical Value (CV) is the average of the CV for a Newman-Keuls test, 
in which the protection level is equal to $\propto$ for all ordered pairs, and the Tukey (a), in which the protection leve1 is equal to $\alpha$ for a11 tests no matter how far apart. Hence, as a test, Tukey (b) is somewhat more conservative, making fewer Type I errors, than the Newman-Keuls, but more powerful, making fewer Type II errors, than the Tukey (a). For the multiple comparisons, it was predicted that statistical differences would be found between experimental groups lying on the same bipolar dimension, on constellations of octant scores assumed to express that given dimensionality. For example, it is assumed that octants $8,1,2$ are measures which express the positive pole of the Dominance dimension. Therefore one-should find a significant difference between the Dominance and Submission experimental groups which lie on the same dimension. However, since computation of a summary score for a particular dimension does not include the center point octants of the dimension orthogonal to it, one can not predict a difference on this constellation between, for example, Love and Hostility groups.

The constellations of octants taken to be positive expressions of the 4 poles were: DOM $-8,1,2$; SUB $-4,5,6$; LOV $-6,7,8$; and HOST $-2,3,4$ (see Figure 1). 
Before hypotheses could be tested it was necessary to determine if any ICL profile differences existed between the classes which would be pooled to make up an experimental group. This was done and no statistical differences were found between the profiles of the two classes. Therefore classes were pooled without reservation.

Genera1 Hypotheses

Results of the main analysis are presented in Table 1. A review of this table reveals that all 3 hypotheses dealing with the profile analysis were significant beyond the level pr.01.

The reader will recall that, in a design of this nature, of major interest is a test of the variance contributed by the Group (A) $X$ Octant (B) interaction; for it is here that we find an answer to the question of parallel profile shapes. A graphic presentation of this interaction, which vividly illustrates the variance, can be found in Figure 2.

A test of the variance contributed by the Groups (A), answers the question of whether or not the group profiles are on the same level. The resulting $F$ for $A$ was significant at the leve1 of $\mathrm{p} r .01$, a finding not at a11 surprising.

Finally, in profile analysis one is usually much less interested in the question concerning equal means among the tests, which is answered by a test of the variance contributed by the octant means (B). The resulting $F$ was, however, significant at the level of p 8.01 .

Before leaving these genera1 hypotheses, a comment on the assumptions underlying the approximate Multivariate Analysis of 
TABLE 1

Analysis of Variance

Testing the General Hypotheses

\begin{tabular}{|c|c|c|c|}
\hline Source & dff & $\underline{\mathrm{MS}}$ & $\underline{\mathbf{F}}$ \\
\hline Groups (A) & 3 & 146.17 & $8.15 *$ \\
\hline Octants (B) & 7 & 72.42 & $14.20 * *$ \\
\hline Subjects (C) & 196 & 17.93 & \\
\hline$A \times B$ & 21 & $\quad 1,402.84$ & $275.06 * * *$ \\
\hline $\mathrm{B} \times \mathrm{C}$ & 1372 & 5.10 & . \\
\hline Tota1 & 1599 & & \\
\hline$* p \& .01 ;$ & $(3 / 196)$ & & \\
\hline$* * \mathrm{~g}<.01 ;$ & $(1 / 196)$. & & $\cdot$ \\
\hline$* * *$ p $\quad .01$ & $(3 / 196)$ & & \\
\hline
\end{tabular}




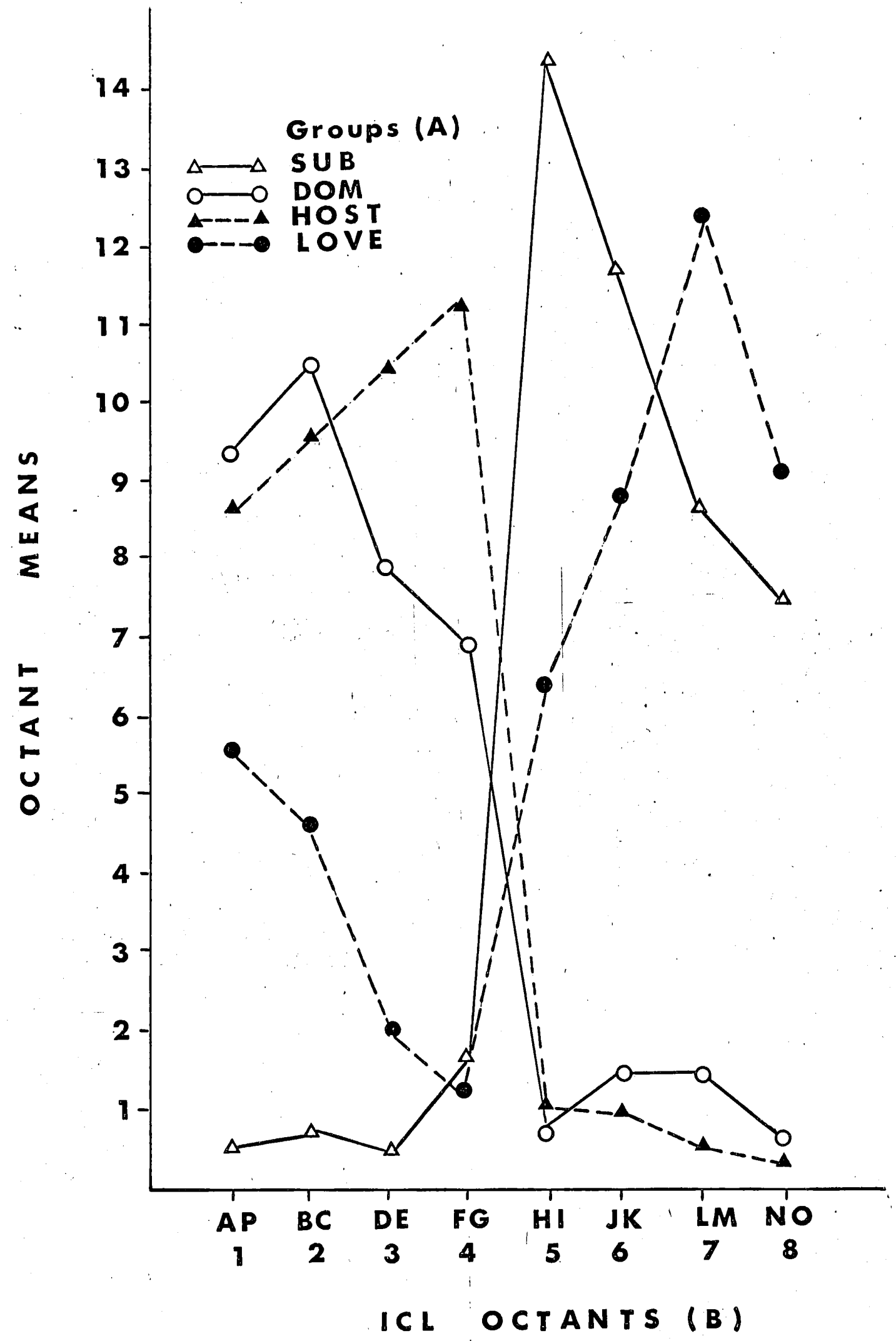

Figure 2. Group by octant interaction. 
Variance procedure of profile analysis (Greenhouse \& Geisser, 1959) should be made for those readers unfamiliar with it. This mode1 assumes that the $\underline{\mathrm{k}}$ variables have a multinormal distribution with an arbitrary variance-covariance matrix and that they be homogeneous from group to group. Should the matrices differ however, an adjustment to the degrees of freedom, resulting in conservative $\underline{F}$ tests, must be made. Therefore, this investigation adjusted the degrees of freedom for the $\underline{F}$ tests of the A X B interaction and the $B$ main effect and so noted these in Table 1.

Specific Hypotheses

Results of the multiple comparisons tested by the Tukey (b) procedure are presented in Table $2,3,4$, and 5.

Examining each set of comparisons in turn, one finds that on the octant constellation expressing the Dominance pole -- 8,1,2, the group viewing the Submissive characterization differed significantly from all other groups. Of particular importance to validation however, is its difference from the Dominance group, since these lie on the same bipolar dimension.

Comparisons between groups on the octant constellation expressing the Hostility pole -- 2,3,4, revealed that all groups were significantly different from each other. Note that the Hostility and Love groups were significantly different from each other.

Comparisons performed over the constellation taken as a measure of Submission -- 4,5,6, found all groups, except Hostility and Love, to differ from each other. Important again is the Dominance verses 


\section{TABLE 2}

Multiple Comparisons between Group Sums on Octant Constellations Expressing ICL Dimensions

Tukey (b) Procedure

DOMINANCE

Octants $8,1,2$

\begin{tabular}{|c|c|c|c|c|c|}
\hline Groups & & Sub & Host & Love & Dom \\
\hline & Totals & 431 & 917 & 953 & 1011 \\
\hline Sub & 431 & $\ldots$ & $486 *$ & $522 *$ & $580 *$ \\
\hline Host & 917 & & $-\infty$ & 36 & 94 \\
\hline Love & 953 & & & $--\infty$ & 58 \\
\hline
\end{tabular}


TABLE 3

Multiple Comparisons between Group Sums on Octant Constellations Expressing ICL Dimensions

Tukey (b) Procedure

HOSTILE

Octants $2,3,4$

\begin{tabular}{cccccc}
\hline Groups & & Sub & Love & Dom & Host \\
\hline & Totals & 140 & 389 & 1255 & 1561 \\
\hline Sub & 140 & $\ldots$ & $249 *$ & $1115 *$ & $1421 *$ \\
Love & 389 & & $-\ldots$ & $866 *$ & $1172 *$ \\
\hline Dom & 1255 & & & & \\
\hline
\end{tabular}


TABLE 4

Multiple Comparisons between Group Sums on Octant Constellations Expressing ICL Dimensions

Tukey (b) Procedure

SUBMISSIVE

Octants $4,5,6$

\begin{tabular}{|c|c|c|c|c|c|}
\hline Groups & & Dom & Host & Love & Sub \\
\hline & Totals & 432 & 660 & 818 & 1322 \\
\hline Dom & 432 & $-\infty$ & $228 *$ & $386 *$ & $890 *$ \\
\hline Host & 660 & & $\ldots$ & 158 & $662 *$ \\
\hline \multirow[t]{2}{*}{ Love } & 818 & & & $-\infty$ & $504 *$ \\
\hline & & & & & \\
\hline
\end{tabular}


TABLE 5

Multiple Comparisons between Group Sums on Octant Constellations Expressing ICL Dimensions

Tukey (b) Procedure

$$
\text { LOVE }
$$

Octants $6,7,8$

\begin{tabular}{|c|c|c|c|c|c|}
\hline \multirow[t]{2}{*}{ Groups } & & Host & Dom & Sub & Love \\
\hline & Totals & 82 & 152 & 1382 & 1505 \\
\hline Host & 82 & $=-$ & 70 & $1300 *$ & $1423 *$ \\
\hline Dom & 152 & & $\infty$ & $1230 *$ & $1353 *$ \\
\hline Sub & 1382 & & & $-\infty$ & 123 \\
\hline$\underline{p}$ & & & & & \\
\hline
\end{tabular}


Submissive comparison.

Finally, the last set of comparisons performed over the constellation expressing the Love pole $--6,7,8$, revealed a significant difference between the groups: Hostility and Submission, Dominance and Submission, Dominance and Love, and the important comparison of Hostility verses Love. No difference was found between the groups: Dominance and Hostility, and Submission verses Love.

Now that we have taken a closer look at the results of the multiple comparisons on each of the octant constellations, it becomes apparent that in each set of comparisons the group at the opposite pole of the dimension (measured by a constellation opposite the one listed for the table) was significantly different from all of the other groups. This held for all sets of comparisons except that of Love; in this instance the Hostility group had a lower sum than the Dominance but not significantly different. Such a finding is to be expected since the octants 1isted are not additive to the pole's measure (i.e., the Dominance octants -- $8,1,2$, load negatively on the Submissive pole). Implicit in this finding is a statement aiding the validation process, for now one can a1so define what octant constellations do not contribute to the measure of a pole.

To summarize, as predicted, the difference between groups lying on the same bipolar dimension, when tested on a constellation of octants assumed to express that dimension, was significant at $p \$ .01$. But as predicted, a difference between groups lying or thogonal to the dimension could not be predicted. For instance, no difference between Hostility 
and Love groups was found on octant constellations taken to express the Dominance-Submissive dimension. But a significant difference was found between the Dominance and Submission groups on octant constellations expressing the Love-Hostility dimension. Perhaps it remains for replication to demonstrate that this unpredictability may in fact be predictable. 


\section{DISCUSSION}

The results of Briar and Bieri's (1959) study of the ICL brought into question LaForge and Suczek's formulations concerning the interpersonal variables (either 16 ths or 8 ths) assumed to measure the underlying dimensions of the ICL and the rationally derived formulae used to compute the summary scores Dom and Lov. But as was mentioned earlier in the introduction, this writer feels that Briar and Bieri made several errors in their design, the most serious of which was the use of an adulterated ICL for validation purposes. Yet if Briar and Bieri's study provided no methodologically sound results, what other evidence exists for the validity of the summary score formulae, and for that matter, the dimensions taken to underly the ICL?

A search of the published literature revealed ample indirect evidence to support the existance of 2 bipolar dimensions underlying the ICL, but little work had been done on the matter of the summary scores; above all, no inferential studies to support their validity.

The results of the present study, however, support the assumption that 2 bipolar dimensions underly the ICL and that the original formulations of LaForge and Suczek concerning the interpersonal variables taken to be their measure are correct.

Unfortunately, as in most studies, the results are not without limitations. The use of college students as $\underline{S}$, of course limits its -generality to the broad populations in which the ICL has found use. Secondly, the results can only be taken as an indirect validation of the summary scores Dom and Lov. The usual concurrent validation method which so often sets the psychometrician's mind at rest is not 
immediately possible for the ICL summary scores, simply because no other validation instrument exists proporting to measure that which the summary scores Dom and Lov measure.

However, the problem of validating the summary scores can, and has here, been broken into 2 components. On the one hand, one can be primarily concerned with the interpersonal variables taken to be measures of either dimension; while on the other, one can concern himself with the order and weights applied to the interpersonal variables. This study directly investigated the interpersonal variables assumed to be a measure of a given dimension; and its results, given the sampling limitations, clearly support the formulations of LaForge and Suczek in regards to the interpersonal variables assumed to be measures of the ICL's underlying dimensions.

Now what can be said for the order of interpersonal variables and the weights applied to them in the formulae? On this matter, it is the author's opinion that no amendment of the formulae is needed. After al1 the formulae have been constructed on sound mathematical constructs to be consistent with the original circumplex. This construct validity supported by the present inferential study and many more indirect investigations, seems sufficient to warrant the continued use of the summary scores Dom and Lov. 
Bentler, P. Interpersonal Check List. In The Sixth Mental Measurement Yearbook. (O.K. Buros, Ed.) Highland Park, N. J.: Gryphon Press, 1965, 267-268.

Briar, S. ,\& Bieri, J. A factor analytic and trait inference study of the Leary Interpersonal Check List.' Journal of Clinical Psychology, 1963,19 , 193-198.

Foa, U. G. Convergences in the analysis of the structures of interpersonal dimension of personality. Psychological Review, $1961, \underline{68}, 341-353$.

Greenhouse, S. W., \& Geisser, S. On methods in the analysis of profile data. Psychometrika, 1959, 24, 95-112.

LaForge, R. Research use of the ICL。: Oregon Research Institute Technical Report, 1963, 3 .

LaForge, R., \& Suczek, R. F. The interpersonal dimension of personality: III. An interpersonal check 1ist. Journal of Personality, 1955, 24, 94-112.

Leary, T. F. Interpersonal diagnosis of personality. New York: Ronald Press, 1957.

Owens, A. G. The assessment of performance in small antarctic groups. Part III. Factor analysis of Leary Interpersonal Check List items. Report 10/67. Psychological Research Unit, Australian Military Forces.

Wiggins, Nancy A. Structural aspects of the interpersonal system of personality diagnosis Level II. Unpublished master's thesis, Stanford University, 1961.

Winer, B. J. Statistical principles in experimental design. New York: McGraw-Hil1, 1962, 87-88. 
APPENDIX 
Here is a list of words and phrases which describe the way people behave in relation to one another and an answer sheet with answer spaces numbered to correspond to the words on the list. You will use the list of words to describe a gentleman, Mr. Tom Early, whom you are about to see, via videotape, in a variety of role played situations with other people.

After you view the tape, go through the list and select a11 those words and phrases which, in your opinion, describe Mr. Early. When an item describes him, make a dark horizontal mark with a No. 2 pencil between the dotted lines in the A column on the answer sheet for that item. Make your mark as 1 ong as the pair of 1ines, and completely fill the area between the pair of lines. If you change your mind, erase your first mark COMPLETELY. Make no stray marks, as they will be mis-read.

For those items which do not, in your opinion, describe him, leave the space on the answer sheet blank. Your first impression is best; so go through the list as quickly as you can, making a mark when the word or phrase describes him, leaving the A column blank when the item does not describe him. 
1. Able to give orders

2. Appreciative

3. Apologetic

4. $A b l e$ to take care of self

5. Accepts advice readily

6. Able to doubt others

7. Affectionate and understanding

8. Acts important

9. Able to criticize self

10. Admires and imitates others

11. Agrees with everyone

12. Always ashamed of self

13. Very anxious to be approved of

14. Always giving advice

15. Bitter

16. Bighearted and unselfish

17. Boastful

18. Business like

19. Bossy

20. Can be frank and honest

21. Clinging vine

22. Can be strict if necessary

23. Considerate

24. Cold and unfeeling

25. Can complain if necessary

26. Cooperative

27. Complaining

28. Can be indifferent to others

29. Critical of others.

30. Can be obedient

31. Crue1 and unkind

32. Dependent

33. Dictatorial

34. Distrusts everybody
35. Dominating

36. Easily embarrassed

37. Eager to get along with others

38. Easily fooled

39. Egotistical and conceited

40. Easily led

41. Encouraging others

42. Enjoys taking care of others

43. Expects everyone to admire him

44. Faithful follower

45. Frequent1y disappointed

46. Firm but just

47. Fond of everyone

48. Forceful

49. Friend $1 y$

50. Forgives anything

51. Frequently angry

52. Friendly all the time

53. Generous to a fault

54. Gives freely of self

55. Good leader

56. Gratefu 1

57. Hard-boiled when necessary

58. Helpfu1

59. Hard-hearted

60. Hard to convince

61. Hot-tempered

62. Hard to impress

63. Impatient with others' mistakes

64. Independent

65. Irritable

66. Jealous

67. Kind and reassuring

68. Likes responsibility 
69. Lacks self-confidence

70. Likes to compete with others

71. Lets others make decisions

72. Likes everybody

73. Likes to be taken care of

74. Loves everyone

75. Makes a good impression

76. Manages others

77. Meek

78. Modest

79. Hardly ever talks back

80. Often admired

81. Obeys too willingly

82. Often gloomy

83. Outs poken

84. Overprotective of others

85. Often unfriendly

86. Overs ympathetic

87. Often helped by others

88. Passive and unagressive

89. Proud and self-satisfied

90. Always pleasant \& agreeable

91. Resentfu1

92. Respected by others

93. Rebels against everything

94. Resents being bossed

95. Self-reliant and assertive

96. Sarcastic

97. Self-punishing

98. Self-confident

99. Self-seeking

100. Shrewd and calculating

101. Self-respecting
102. Shy

103. Sincere $\&$ devoted to friends

104. Selfish

105. Skeptical

106. Sociable and neighborly

107. Slow to forgive a wrong

108. Somewhat snobbish

109. Spineless

110. Stern but fair

111. Spoils people with kindness

112. Straightforward \& direct

113. Stubborn

114. Suspicious

115. Too easily influenced by friends

116. Thinks only of self

117. Tender and soft hearted

118. Timid

119. Too lenient with others

120. Touchy and easily hurt

121. Too willing to give to others

122. Tries to be too successful

123. Trusting and eager to please

124. Tries to comfort everyone

125. Usually gives in

126. Very respectful to authority

127. Wants everyone's love

128. We11 thought of

129. Wants to be led

130. Will confide in anyone

131. Warm

132. Wants everyone to like him

133. Will believe anyone

134. We11-behaved

Form 4 ORI $10 / 63$ 